\title{
La huella Adriana. Olivetti: conexiones urbanas, sociales y culturales entre Ivrea y Merlo*
}

\author{
Adriano's path. Olivetti: urban, social and cultural \\ connections between Ivrea and Merlo
}

Francisco Sambrizzi

\section{Resumen}

La cuestión acerca de las prácticas de trabajo en relación a una renovada forma de vida en comunidad ha dado lugar a múltiples propuestas utópicas y sólo algunas concreciones. En Ivrea las motivaciones de un hombre fascinado por la técnica al servicio del espíritu humano continúa hoy como referente indiscutido identificando una ciudad con una marca: Olivetti. Su sede extramuros de Buenos Aires, instalada en la localidad de Merlo e inaugurada en 1960, abastecería a un mercado en crecimiento que aprovechaba coyunturas latinoamericanas. Se investigará el rol que este emprendimiento significó para la sociedad, analizando aquellos mecanismos de acción mediante los cuales se proyectó, ejecutó y comunicó una doctrina social sobre la producción industrial vinculada estrechamente a una comunidad.

Palabras clave: Olivetti; industria; Buenos Aires; urbanismo; comunidad.

\begin{abstract}
Questions about labor practices in relation to a renewed form of community life have led to multiple utopian proposals and only some concretizations. In Ivrea, the motivations of a man fascinated by technique at the service of the human spirit continue to this day, undoubtedly identifying the city with a brand: Olivetti. Headquartered outside the city walls, in the region of Great Buenos Aires, installed in the town of Merlo and inaugurated in 1960, the factory supplied a growing market that took advantage of the Latin American conjuncture. This article investigates the role that this venture played in the society, and analyzes the action mechanisms that were used to design, execute and communicate a social doctrine that linked industrial production to the community.
\end{abstract}

Keywords: Olivetti; industry; Buenos Aires; urbanism; community. 
Y el mundo marcha hacia días más radiantes y dichosos, pero con una sola condición: que las inmensas fuerzas materiales puestas hoy a disposición del hombre sean dirigidas hacia finalidades, hacia metas espirituales.

Adriano Olivetti (1962)

\section{Introducción}

La cuestión acerca de las prácticas de trabajo en relación a una renovada forma de vida en comunidad ha dado lugar a una multiplicidad de propuestas y sólo algunas concreciones. Ya en Inglaterra de la primera mitad del siglo XIX se habían destacado los Ilamados utópicos socialistas (Robert Owen, Charles Fourier, Ethiene (abet) con sus ideas de organización que integraban sociedad, trabajo y propiedad. En oposición a los modelos progresistas, el urbanismo de corriente culturalista ${ }^{1}$ ha debatido acerca de proyectos de objetivos humanistas, compactos y plurifuncionales cuyo mayor referente fue la garden city de Ebenezer Howard de 1898, surgida como respuesta descentralizadora frente al impacto de la revolución industrial sobre el territorio y su presión expansiva hacia los suburbios. ${ }^{2} \mathrm{Ya}$ entrado el siglo XX y en el contexto de la gran metrópoli, el sociólogo estadounidense, Lewis Mumford (1934 y 1938), retomaría y ampliaría estos temas con una mirada multidisciplinar que imaginaba el futuro de la civilización en su integración de planeamiento, cultura y técnica. Por ese entonces, en Ivrea, provincia italiana de Turín, las motivaciones de un hombre fascinado por la técnica al servicio del espíritu humano continúa hoy como referente indiscutido identificando una ciudad con una marca: Olivetti.
Adriano Olivetti concibió su proyecto de desarrollo industrial acompañado de un paradigmático planeamiento social y urbano. Continuó y amplió el emprendimiento familiar hasta transformarlo en una icónica organización de la eficiencia productiva. Su visión de la fábrica como establecimiento modelo al servicio de la comunidad, como potenciadora de las virtudes y prácticas humanas derivó en una comprometida política laboral y de vivienda en relación a instalaciones sociales, culturales y de trabajo. Abogando siempre por la imperiosa necesidad de planificación en un país desbordado por la vorágine del crecimiento edilicio de la posguerra, se observará con agrado su activa participación en institutos y proyectos de planeamiento urbano y de vivienda. Sus escritos, sus proyectos editoriales e incluso su actividad política cristalizada en la fundación del Movimento Comunità no hacen más que direccionarlo hacia el mismo objetivo. La demostración de interés por la arquitectura, con encargos edilicios a referentes italianos y una devoción especial por la figura de F. L. Wright configuran aún más compleja esta enorme personalidad.

Mientras tanto Olivetti crecía y se expandía. La fábrica de Ivrea se ampliaba y nuevas sedes dentro y fuera del país aparecían 
en escena sellando el carácter de la empresa, convertida ya en una multinacional que incorporaba a la estadounidense Underwood y contribuía mediante la exigencia de perfección a condensar el imaginario de excelencia del diseño italiano. Un diseño que adquiría por entonces una férrea voluntad de comunicación y visibilidad en el encuentro de la síntesis entre los productos industriales, la publicidad gráfica y la búsqueda de una arquitectura adecuada para el proceso del trabajo que abarcaba desde la fabricación hasta la exposición de los productos.

Latinoamérica no fue la excepción. Ya comenzada la década de 1960, y poco después de la prematura muerte de Adriano, se inauguraron fábricas en México, San Pablo y Buenos Aires. Ésta última fue instalada en la localidad suburbana de Merlo $^{3}$ mientras las oficinas centrales ocupaban varios pisos del flamante edificio Brunetta en la ciudad porteña.

El debate acerca de la expansión ilimitada de la ciudad sobre el territorio ya se había instalado en Argentina a partir de la década de 1930 influenciando la posterior acción desdoblada de planeamiento urbano y suburbano-rural durante el peronismo (Ballent, 2005). Resultará por lo tanto llamativo que el emprendimiento fabril se sitúe en una localidad correspondiente a la grilla de dispersión suburbana de Buenos Aires ante la cual el modelo inglés de ciudad jardín admirado por Adriano vendría a alzarse como alternativa (Gorelik, 2010). Incluso la materialización del grupo de viviendas para trabajadores será concebida como un proyecto ex nihilo en una manzana aislada de esa grilla.

En cuanto a la producción industrial en Argentina el presente trabajo se sitúa en medio de un complejo contexto de relaciones y tensiones entre pensamiento, empresa y políticas de Estado que sólo en ocasiones lograron aunarse en una dirección común (De Ponti, 2011; Crispiani, 2011). Si bien habrá que indagar en las medidas del gobierno peronista (1946-1955) que alentaron la radicación de capitales italianos, el período de mayor importancia en cuanto a la actividad de Olivetti pertenece al de un momento de "péndulo económico" donde el estado oscilaba entre el fomento de políticas desarrollistas y liberales, lidiando con intereses contrapuestos de corporaciones empresariales, grupos sindicales, facciones militares, un peronismo proscripto y los primeros indicios de insurgencia terrorista (Míguez, 2015).

Se investigará aquí el rol que el emprendimiento de Merlo significó para la sociedad. El enfoque será puesto en objetivos y motivaciones más allá del hecho concreto de abastecer un mercado en crecimiento que aprovechaba coyunturas económicas - la Asociación Latinoamericana de Libre Comercio y la llamada "industrialización sustitutiva de importaciones" (Halperin, 2008). Será de interés vislumbrar tentativas de concreción de los roles sociales y urbanos que se hallaban ya vigentes en la sede matriz. Se analizarán aquellos mecanismos de acción mediante los cuales se proyectaron, ejecutaron y comunicaron iniciativas residenciales y de equipamiento, actividades culturales y educacionales; la construcción, en fin, de un medio ambiente en torno al desarrollo de una propuesta unificadora de eficacia productiva y diseño. Un modelo urbano regional y pragmático planificado y decantado en Ivrea intentará ser trasladado a sitios donde razones económicas 
aconsejan asentamientos industriales. La búsqueda consistirá en descubrir hasta qué punto es posible reproducir, fuera de su lugar de origen, los objetivos sociales de una empresa multinacional de reconocida identidad por sus logros de integración entre técnica y cultura, analizando en particular su alcance y contexto en el proyecto ejecutado en Merlo. Se perseguirán de esta manera los rastros, la "huella adriana" de iniciativas lejanas en el espacio y en ausencia de su ideólogo ya fallecido ¿Cuál será la posibilidad de éxito? ¿Es acaso un sistema susceptible de ser exportado y repetido? ¿Qué condicionantes o alteraciones locales serán relevantes a evaluar? ¿Cuál fue en definitiva el destino de estas utopías?

La investigación se estructurará en dos partes; en primer lugar se buscarán las ideas, antecedentes y referentes que forjaron la comunidad de Adriano Olivetti. Su legado escrito y edilicio será analizado como portavoz de un proceso de elaboración crítico regional y comunal a la vez que aglutinador de experiencias diversas. En segundo lugar, el traslado de la propuesta al contexto argentino obligará introducir algunas consideraciones sociales, políticas y económicas. Luego, la materialización urbana, social y cultural será estudiada en las distintas iniciativas no vinculadas directamente con los requerimientos de producción y comercialización. Las construcciones complementarias aledañas a la fábrica y la coordinación de acciones institucionales abiertas a la comunidad serán la base de evaluación de los objetivos planteados.

\section{Olivetti en Ivrea}

\section{En blanco}

En 1959 Edizioni di Comunità, la casa editorial fundada por el mismo Adriano Olivetti publicaba Citta del/'Uomo, una recopilación de diversos ensayos suyos escritos entre 1951 y 1959. El libro expone su pensamiento y será una referencia fundamental en la presente investigación. Sus motivaciones, que oscilaban entre la producción industrial, el urbanismo y la política, se verán reflejadas en el desarrollo del establecimiento de Olivetti en Ivrea e intentarán ser aplicadas en las nuevas sedes realizadas durante la expansión de la empresa entre las décadas de 1950 y 1960.

El concepto de responsabilidad social empresarial, concerniente al cuidado de las consecuencias sociales de las decisiones empresariales integradas a la búsqueda de ganancias y optimización de recursos, se caracterizaba, en sus inicios a mediados del siglo $\mathrm{XX}$, por su fuerte acento personalista proveniente de su fundador (Tovar e Valdes de la Vega, 2009). Por ese entonces, en el marco de la aún no institucionalización de este rol ante empleados, comunidad y medio ambiente, se suponía que "cuanto mayor el nivel de desarrollo, mayor será la influencia de factores culturales no económicos sobre la decisiones empresarias" (Cochran y Reina, 1965). Nada más cierto y aplicable al caso de Olivetti en Italia, donde la empresa ejerció una influencia notable no sólo en todas las ramas del diseño, 
las artes y la arquitectura, sino también en la planificación urbana y política de un país que, impulsado por la exitosa reconstrucción de posguerra necesitaba encontrar lineamientos para encauzar sus acciones.

La propuesta consistirá primero en estudiar el marco de referencia, la base conceptual urbana y social sobre la cual se elaboraron luego las premisas que excederían los objetivos económicos de una empresa privada y eran prácticamente inéditos en el contexto global al momento de su formulación, obteniendo tal reconocimiento a nivel público hasta el punto de no poder concebir esta pequeña región italiana separada de esa empresa.

\section{Pensamientos publicados}

La calidad de la identidad corporativa y publicitaria de Olivetti es observada primeramente en la atención otorgada a la comunicación interna de la empresa: desde los primeros Foglio Comunicazioni interne de 1939, continuando con el Bolletino Interno Olivetti, la Rivista Olivetti, el Giornale di Fabbrica Olivetti y las Notizie Olivetti aparecidas en 1952 (Associazione Archivio Storico Olivetti), constituyen todos documentos de relevancia que atestiguan la necesidad - institucional y personal de Adriano - por comunicar ideas y saberes. Las Edizioni di Comunità, iniciativa fundada en 1946 en reemplazo de las anteriores Nuove Edizioni Ivrea de 1942, fueron las responsables de introducir en Italia una gran variedad de autores multidisciplinarios cuyas ideas solían ir de la mano con el objetivo de Olivetti de formar una síntesis entre técnica y cultura.

El origen de sus propuestas procedería principalmente de los Estados Unidos, país al que viajó en 1925 en búsqueda de innovaciones industriales y del que regresó con una particular admiración por el fordismo vigente. La estrecha relación entre Italia y Estados Unidos a partir de la década de 1950 había provocado un intercambio cultural de autores y movimientos artísticos hasta el momento poco difundidos entre ambos países, por lo que incluso en ocasiones hacen pie en Italia referentes europeos a través de su acción y divulgación estadounidense. Es así como, en el campo de la planificación, la urbanística y la arquitectura, la editorial fundada por Adriano tradujo textos de autores como Lewis Mumford (1954, 1957, 1959), Richard Neutra (1956), Sigfried Giedion (1954) y, ya por otras vías, hasta el mismo Le Corbusier (1957, 1960).

Las diversas publicaciones periódicas de las que Edizioni di Comunità formó parte proponían un alto nivel intelectual y gráfico, cierta apertura ideológica y una gran variedad temática, obteniendo pronto reconocimiento en amplios sectores de público. El periódico mensual de política y cultura Comunità, identificado por momentos con el partido político Movimento Comunità de Adriano, hacía su aparición en 1946 y tendría vigencia por casi medio siglo. Las revistas especializadas generaban amplitud de contenidos científicos, técnicos, sociales y artísticos desde Tecnica ed Organizzazione, periódico donde Adriano escribía ensayos sobre tecnología, economía y sociología industrial, hasta en la Rivista di Filosofia, relanzamiento de una iniciativa 
existente o la revista bimestral de arte internacional Sele Arte. En ocasiones Adriano Olivetti también participaba o apoyaba proyectos ya vigentes, integrándolos dentro de la editorial o bien solventándolos, como fue el caso de la revista de arquitectura CasabellaContinuità. Dentro de este tópico existieron tres publicaciones de envergadura editadas por Olivetti: Metron - Architettura, Zodiac y Urbanistica.

Metron - Architettura, la revista internacional de arquitectura impulsada por Bruno Zevi y la Associazione per I'Architettura Organica (A.P.A.O.), rescatada y editada entre 1950 y 1954 por Edizioni di Comunità, sería la encargada de difundir las obras de Frank Lloyd Wright en Italia (Casciato, 1999). Fue de hecho quien publicó en 1951 la exhibición Sixty Years of Living Architecture dedicada al casi olvidado maestro estadounidense en el Palazzo Strozzi de Florencia donde se expuso su Broadacre City. Sus postulados acerca de la congruencia entre arquitectura y democracia eran bien aceptados por el público italiano, especialmente por aquellos socialistas que, como Zevi, habían luchado recientemente en la Resistenza contra el régimen fascista. El mismo Adriano se identificaría estrechamente con las utopías urbanas de Wright atraído por su reivindicación del regionalismo: en su ensayo "Urbanismo y libertades locales" citaba un largo pasaje de When democracy Builds ${ }^{4}$ donde se llamaba a abandonar el "hervidero humano" de la metrópolis la cual se encontraba alejada de la escala humana; renunciar a la opresión de la verticalidad y buscar la "horizontalidad del coche, del teléfono, del telégrafo" (Olivetti, 1956 in Olivetti, 1962, p. 72).
La revista internacional de arquitectura contemporánea Zodiac editada por Bruno Alfieri $^{5}$ entre 1957 y 1963, publicada semestralmente por Edizioni di Comunità y cuyo presidente era el mismo Adriano, incluía obras y artículos de los reconocidos maestros en su idioma original, ${ }^{6}$ algunos números temáticos sobre países como EE.UU. (n. 8, 1961) y España (n. 15, 1965) y algunas rarezas como la aparición en el número 5 de 1959 de una declaración de Le Corbusier sobre la muerte de Frank Lloyd Wright.

En 1949 Adriano Olivetti financió el resurgimiento de la revista trimestral Urbanistica, el órgano oficial del Istituto Nazionale di Urbanistica, del cual fue presidente (1950-1960) y director de la revista (1949-1952) donde escribiría sobre planeamiento urbano. ${ }^{7}$ Transformada inmediatamente en un destacado referente internacional, se publicaron ensayos y planificaciones locales y extranjeros, comportándose también como divulgador del regionalismo anglosajón ejemplificado en los proyectos confeccionados por la Regional Planning Association of America (RPAA) ${ }^{8} \mathrm{y}$ de la Tennessee Valley Authority. ${ }^{9}$ Ya en su primer número aparecía la traducción de un artículo de Lewis Mumford (1949a) titulado Planificazione per le diverse fasi della vita (Munford, 1949a), y en el segundo una biografía de suya (Mumford, 1949b). A lo largo de sus ediciones se divulgaron las ideas de las garden cities inglesas y las new towns estadounidenses (Imagen 1), incluyendo proyectos de Richard Neutra y al mismo Wright, cuya exposición de 1951 también fue publicada. $^{10}$ 


\section{Imagen 1}

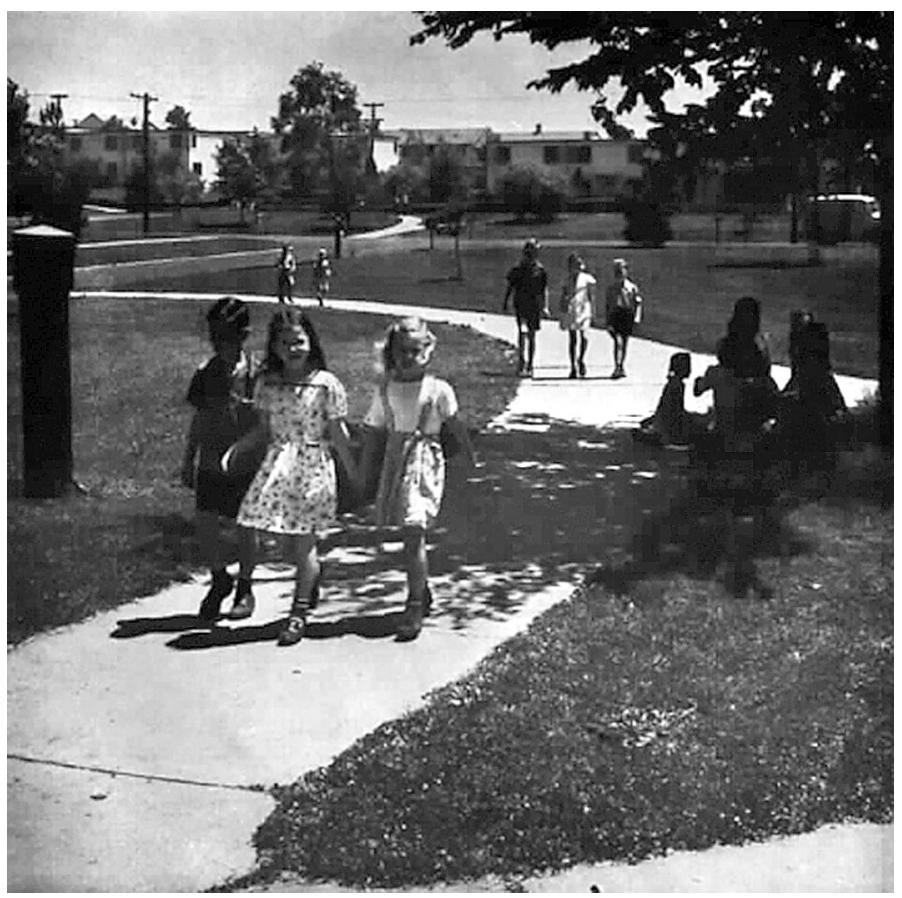

La exhortación de Richard Neutra a planificar para sobrevivir, para "recobrar el equilibrio biológico desaparecido" (Neutra, 1954) es también atendida por Adriano quien cita el caso de Channel Heights como referente de comunidad realizada (Olivetti, 1956, in Olivetti, 1962, p. 76). Este proyecto para los trabajadores portuarios de San Pedro, localidad cercana a Los Ángeles, realizado en 1942 para 600 familias en un terreno ondulado, cuya nivelación se vio facilitada por la introducción de maquinaria moderna, incorporaba distintas tipologías de viviendas, servicios comunitarios y espacios comerciales (Boesiger, 1964c). Las fotografías de Julius Shulman que ilustraban el proyecto se proponían en todo momento captar la vida al aire libre, las comodidades de ambientación interior y las actividades comunitarias en pleno uso (Imagen 2); esta mirada intencionada y publicitaria sería luego imitada en otras greenbelts estadounidenses y en los proyectos de Olivetti, incluyendo el de Merlo.

Quizás haya sido Lewis Mumford quien otorgó el marco de referencia e identificación conceptual a las inquietudes regionalistas que se gestaban por entonces en Estados Unidos y que resultaban evidentemente atractivas en el contexto italiano de restauración tras la guerra. El "orden orgánico" que se impulsaba 
Imagen 2

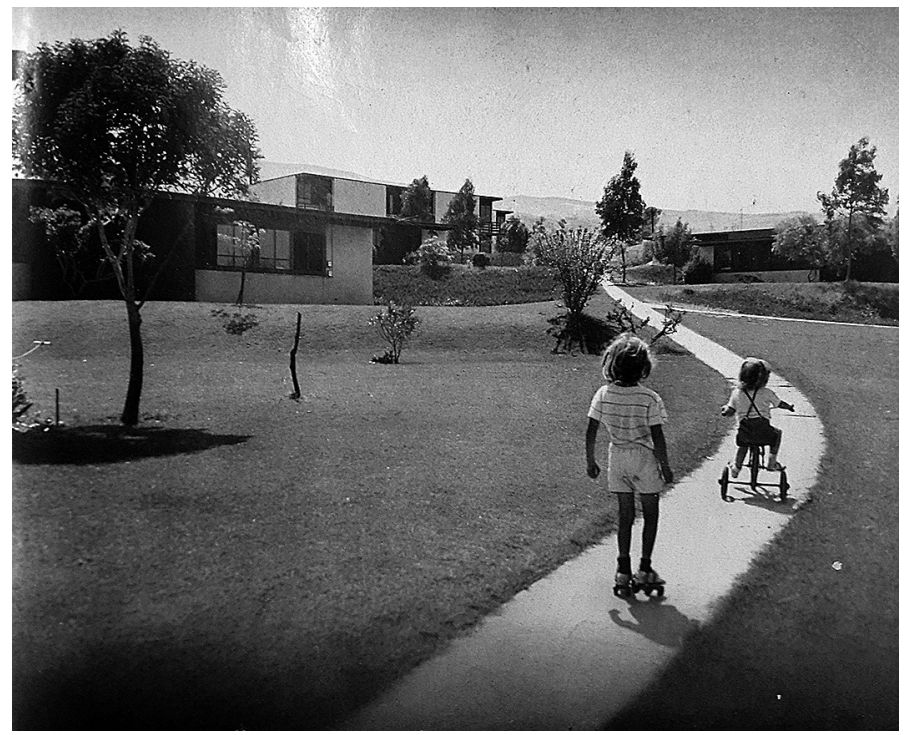

en la vastedad del territorio estadounidense consistía en asimilar un equilibrio constante con el ambiente original y el ambiente heredado, una nueva etapa donde se debía dominar lo mecánico y pasar del "despotismo a la asociación simbiótica, del capitalismo y del fascismo a la cooperación y comunismo básico" (Mumford, 1938, p. 383). La región, definida como la "unidad-área formada por condiciones aborígenes comunes de estructura geológica, de suelo, de clima, de vegetación y de vida animal; reformada y en parte nuevamente definida mediante el establecimiento del hombre" (ibid., p. 461), debía ser objeto de una planificación auténtica y particularizada de la agricultura, la industria y la ciudad. Los temas de diversidad y descentralización regional eran ampliamente tratados por Mumford y serían tomados con entusiasmo por Adriano.
Sería ocioso recordar, tratándose Adriano de un hombre de la industria fascinado por la eficiencia fordista, que no se debía confundir el regionalismo con una suerte de romanticismo arcaizante o de reivindicación artesanal, sino por lo contrario; la fe en el progreso a través de la técnica y la industria se encuentra siempre alentada. Tanto en Wright, Mumford, Neutra y Olivetti se trataba en todo caso de un asunto de planificación. El progreso tecnológico debía ser dirigido racionalmente hacia metas espirituales para que el ser humano pudiera ser restituido al equilibrio con su tierra ya que "vale la pena afrontar una aparente pérdida de rendimiento, a fin de que el hombre pueda evitar la enajenación producida por las fábricas gigantescas y por la opresiva separación de la naturaleza" (Olivetti, 1956, in Olivetti, 1962, p. 74). Por ello, para proporcionar la armonía 
perdida, se debían orientar los esfuerzos en la justa dirección mediante dispositivos que alentaran la descentralización. Ésta consistía, para Adriano, en tres factores a lograr: la implementación de barrios orgánicos unificados, la diseminación de las fábricas a lo largo de las comunidades y el engrandecimiento de los espacios destinados a los servicios sociales y culturales.

\section{Arquitectura para campesinos en Ivrea}

En Ivrea, fuera del casco urbano y en territorios linderos a la primera fábrica construida por Camilo Olivetti sobre Via Jervis fue conformándose un conglomerado edilicio que se proponía dar respuesta a los requerimientos de producción en sintonía con las íntimas motivaciones de Adriano (Imagen 3). Impulsor de los arquitectos italianos modernos de la "segunda generación" encargó obras a figuras como Luigi Figini \& Gino Pollini (siete proyectos), Marcello Nizzoli (siete proyectos asociado en distintas instancias con Annibale Fiocchi o Giuseppe Mario Olivieri), Ignazio Gardella, Ludovico Quaroni \& Adolfo de Carlo, Eduardo Vittoria, Mario Ridolfi \& Wolfang Frankl. De los diecisiete proyectos construidos durante el período de Adriano en Ivrea cinco fueron realizados para las actividades empresariales (oficinas, talleres, centro de ensayos), seis para actividades sociales (servicios sociales, comedor, escuela primaria, jardín de infantes, guardería e iglesia) y otros seis para uso residencial de los empleados. ${ }^{11}$

Escapa a los objetivos de esta investigación analizar la arquitectura presente en Ivrea, ya ampliamente documentada (Zorzi, 1990). Quizás sea de mayor provecho enfocarse

Imagen 3

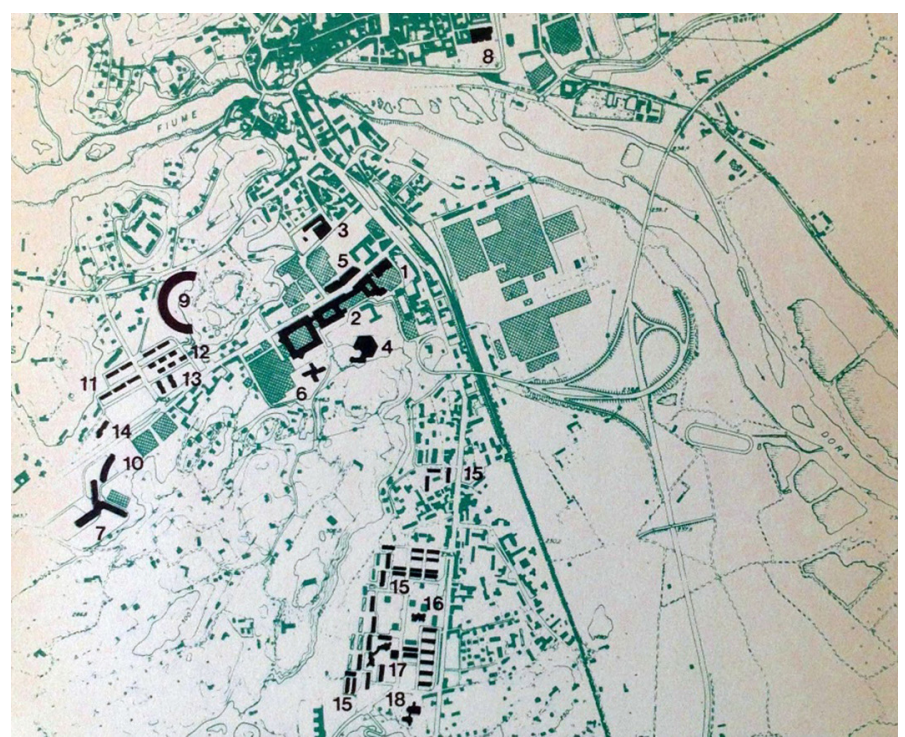


en las premisas que llevaron a construir a lo largo de más de medio siglo esta novedosa Villa Adriana, esta porción de ciudad formada por un collage de edificios de variadas intenciones y procedencias que, a diferencia del emperador romano, estaba presidida por un alcalde. ${ }^{12}$ Ciertos autores sostienen que la valoración de estos arquitectos se debía más bien al carácter internacional de su obra en lugar de una apreciación o identificación con sus propuestas arquitectónicas (Scrivano, 1990). Se apreciaría, siguiendo este razonamiento, su poder de comunicación y transmisión de valores en un mundo que por aquellos años de posguerra parecía buscar vínculos de expansión. El potencial publicitario de la arquitectura de autor en la lógica de la identidad corporativa y los programas de difusión de las grandes empresas estaba por entonces en etapa de elaboración, lo mismo el hecho de una empresa focalizada en el buen diseño industrial promoviendo la buena arquitectura para sus espacios de acción y referencia.

La cuestión acerca de las ideas arquitectónicas y espaciales buscadas por el mismo Adriano surge ante la evidente variedad edilicia construida; ¿existen inquietudes innegociables comunes a todas las obras? En su ensayo "La arquitectura, la comunidad y el urbanismo" reflexiona que el arquitecto siempre "se hace urbanista, quiéralo o no" (Olivetti, 1957, in Olivetti, 1962, p. 106). Las consideraciones hacia el ambiente estarán presentes en su obra y su destino es otorgarle un rostro nuevo a la naciente comunidad; sin realizar concesiones de tipo folklórico sino atendiendo a la "necesidad de radicación, la de encontrar en la tierra, en el paisaje y aún en las tradiciones las formas arquitectónicas" (ibid., p. 104). En su discurso de inauguración en 1955 ante los trabajadores de la fábrica en Pozzuoli proyectada por Luigi Cosenza, Adriano destaca su rigor racionalista y organización que la emparentan con la de Ivrea, y el respeto por la belleza del sitio. "Hemos querido también que la naturaleza acompañara la vida de la fábrica. La naturaleza corría el riesgo de ser repudiada por un edificio demasiado grande, en el que las murallas cerradas, el aire acondicionado, la luz artificial hubieran tratado de transformar día a día al hombre en un ser distinto del que había entrado" (ibid, p. 122). Es por eso que la fábrica fue diseñada "a la medida del hombre justificando así las ventanas bajas y los patios abiertos y árboles en el jardín para excluir definitivamente la idea de una construcción y de un encierro hostil" (ibid.). Efectivamente, la solución en cruz adoptada lograba responder por un lado a la funcionalidad y futuras ampliaciones requeridas y, por el otro, adaptarse a un terreno en pendiente con magníficas visuales al mar.

Las consideraciones arquitectónicas son siempre de índole psicológica. La perdida "civilización de campesinos y pescadores" a la que continuamente hace referencia se había convertido en la de los trabajadores industriales arrancados de su tierra, alejados de la naturaleza, por lo que para evitar el alienamiento y las miserias de esta nueva condición se debía siempre respetar el paisaje percibiéndose con amplitud desde el interior del edificio. Los elementos para lograrlo, en los espacios de trabajo, se encontraban en la eliminación de la masa muraria mediante la 
estructura puntual y la ventana corrida o el curtain wall, sinónimo de transparencia social, como así también en la incorporación de patios y terrazas para humanizar y dignificar el espacio reincorporando la naturaleza en los ambientes cotidianos de la fábrica.

La importancia otorgada al ambiente en el desarrollo de los espacios de referencia humanos en oposición al desarraigo, indiferenciación y homogeneidad de la máquina tiene correlación con las ideas ampliamente difundidas por Mumford, quien fuera el nexo por entonces con las utopías sociales del siglo XIX para repensar el urbanismo anglosajón. Mumford se refería a lo orgánico en términos sociales como "la desaparición de las barreras que separan lo interior de lo exterior, lo consciente de lo inconsciente, y el medio interno del externo"
(Mumford, 1938, p. 383); el hombre, de esta manera, sólo podía tener acceso al ambiente externo por intermedio de la sociedad, lo cual implicaba encontrar su sitio en el territorio haciendo las paces con la técnica.

El complejo llamado "faja de servicios sociales" demostraba la energía dedicada a dar una respuesta concreta a la inquietud de promover el bienestar cultural y ambiental (Imagen 4). Refiriéndose a los objetivos sociales presentes en la fábrica de Ivrea, Adriano la describía como "una empresa de tipo nuevo más allá del socialismo y del capitalismo", una fábrica que "ha dirigido sus finalidades y sus mayores preocupaciones a la elevación material, cultural, social, del lugar donde fue llamada a obrar" y por eso cree en los valores espirituales, cree en los valores de la ciencia, cree en los valores del arte, cree en

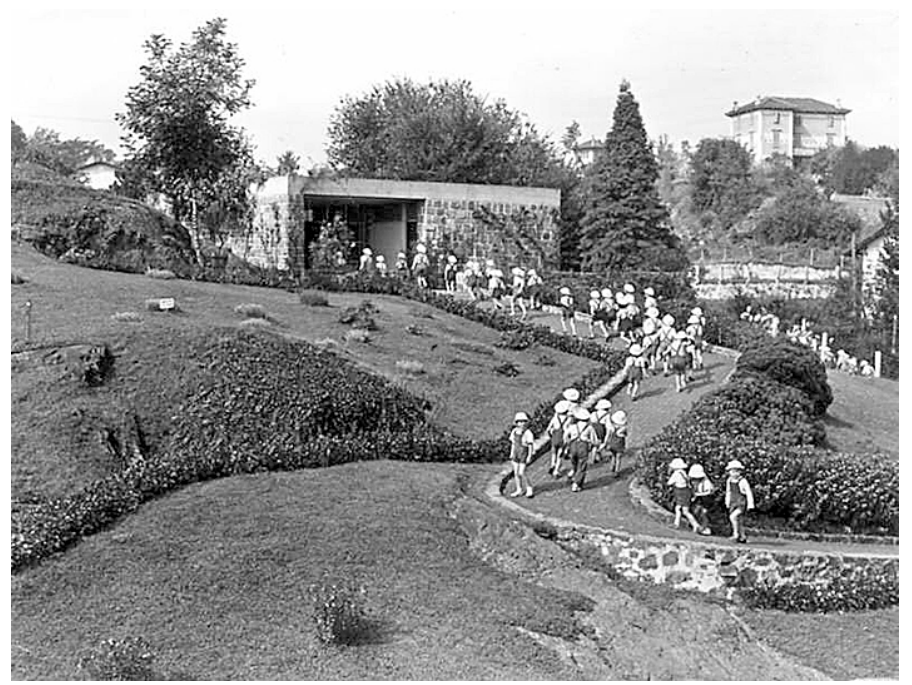


los valores de la cultura, cree en fin, que los ideales de justicia no pueden ser extraños de las contiendas aún no eliminadas entre capital y trabajo (Olivetti, 1955, in Olivetti, 1962, p. 121). De hecho, el sistema cultural en Ivrea cuyo eje era su biblioteca de 90.000 volúmenes adquirió enorme relevancia, como también los ciclos culturales que, entre 1950 y 1964, organizaron 249 conferencias, 71 conciertos de música de cámara, 103 exhibiciones de arte entre otros eventos. Estas acciones eran tanto internas dirigidas a empleados y familiares, quienes en ocasiones acudían en sus dos horas de recreo de almuerzo, como externas abiertas al público.

En el plano urbano, las viviendas para los trabajadores formaban parte de las estrategias ya ensayadas en el Planeamiento para el Valle de Aosta de 1937, el Plan Urbano de Ivrea de 1951, en el Istituto per il Rinnovamento Urbano e Rurale del Canavese fundado por Adriano en 1955 y en el Istituto UNRRA-CASAS; ${ }^{13}$ en todos ellos se estudiaron las relaciones entre espacios agrícolas, industria y vivienda. La localización residencial cercana a los sitios industriales se convertiría en consigna al constituir un derecho de bienestar de todo trabajador para, además de disminuir los trayectos, evitar el desarraigo y lograr la identificación con el propio territorio. De esta manera se pretendía contribuir a la creación de auténticos centros vitales de vida laboral y familiar. En el campo material las necesidades también eran significativamente atendidas mediante tres estándares: reducción del horario laboral, ${ }^{14}$ retribución de salarios más allá del mínimo ${ }^{15}$ y la no aceptación del despido como estrategia económica.

\section{Olivetti en Argentina}

\section{Producción portátil: \\ Olivetti en Argentina}

Olivetti comenzó a operar en Argentina a través de representantes comerciales en 1920 por medio de la firma Curetti \& Cia en Rosario; en 1929 se expandía mediante la creación de la Agencia General Olivetti de Bessona, Grondona \& Cia cuyas sede estaba en Buenos Aires con una sucursal en Rosario y filiales en otros puntos del interior; ya en 1932 se formó Olivetti Argentina para cubrir todo el territorio del país (Associazione Archivio Storico Olivetti). En 1951, en una planta existente en Ramos Mejía, comenzó a producirse la máquina de escribir Lexikon 80; a partir del inmediato éxito obtenido ${ }^{16}$ le siguió la producción de máquinas de calcular. Finalmente, en 1954 Adriano Olivetti encargó al arquitecto italiano Marco Zanuso ${ }^{17}$ el proyecto de la nueva fábrica que comenzaría su construcción en 1958 y se inauguraría en 1960 en Merlo, provincia de Buenos Aires. És justamente en el período de decisión de la instalación productiva en el país, en el período de posguerra, final del peronismo y comienzos del desarrollismo, donde se buscan los incentivos de la empresa ${ }^{18}$ y referencias de la próspera relación política, económica y cultural entre Italia y Argentina para contextualizar la inserción de Olivetti en el escenario local.

La política migratoria del gobierno de Juan Perón tuvo una gran influencia en las relaciones entre ambos países. Las arduas negociaciones para establecer las condiciones 
de selección, traslado y contrato laboral de los migrantes se articulaban a su vez con el interés italiano de prevenir conflictos sociales a causa de la desocupación de posguerra y de hacerse de divisas por medio de las remesas de los inmigrantes, y con el interés argentino de regular su balanza de pagos y de exportación de trigo (Devoto, 2008, pp. 389-399). La diplomacia también jugó su papel, y el viaje de Evita a Italia en junio de 1947 fue el que terminó de aceitar las relaciones. Esta nueva llegada de italianos al país debía así paliar el déficit de mano de obra para "contribuir al progreso de la nación". Se crearon con este objetivo instituciones como la Delegación Argentina de Inmigración en Europa (DAIE) y la Comisión de Recepción y Encauzamiento de Inmigrantes (CREI) y se firmaron varios acuerdos específicos con el país peninsular entre 1947 y $1952^{19}$ para fomentar la llegada de "campesinos y obreros" 20 a quienes se otorgarían facilidades para insertarse en empresas de origen italiano operando en el país. La enorme presencia previa de personas de origen italiano en Argentina generaba, por su parte, una red de conexión que impulsaba la venida de los extranjeros. En medio de polémicas en torno a cuestiones nacionalistas, eugenésicas y racistas, y de críticas en torno a la inmigración regulada que comerciaba con la mano de obra, ${ }^{21}$ se justificaba el fomento de inmigrantes italianos por su mejor asimilabilidad latina, aplicándose a su vez criterios sanitarios y de selección ideológica anticomunista.

En el plano económico, las empresas, que en el período anterior preferían abrir oficinas de comercialización en Argentina en lugar de plantas industriales, ahora elegían instalarse en el país frente a las restricciones de importaciones. A pesar de que algunos autores prefieren evitar el término "industrialización sustitutiva de importaciones" y mencionar en cambio este período como "industrialización por desborde de las empresas trasnacionales de su mercado local" (Schvarzer, 2000, en De Ponti, 2011, p. 15), lo cierto es que ahora hallaban varios incentivos para emplazar sitios de producción en el país. Ya en 1953 Perón modificaba el régimen de inversión extranjera, revirtiendo la tendencia previa de nacionalización y volviendo a abrir las puertas a capitales foráneos (Goldstein y LLuch, 2010, p. 23). Además de poder contar con alta cantidad de empleados connacionales, las empresas italianas eran beneficiadas por créditos ofrecidos por su propio gobierno para las exportaciones de bienes de capital y por acuerdos entre ambos países como la convención ítalo-argentina sobre seguros sociales de 1964 y la promoción de acuerdos bilaterales en materia fiscal a los efectos de evitar la doble imposición de 1966 (Devoto, 2008, p. 415). Se debe resaltar la habilidad de los italianos para moverse satisfactoriamente en el intrincado escenario local, así como el rol de la comunidad peninsular en el país generando vínculos políticos y de negocios, y constituyéndose, además, como potencial mercado de consumidores de productos italianos. En última instancia, como hace notar Devoto, en medio de un contexto local de resistencia hacia multinacionales extranjeras, la simpatía local hacia ellas se debía a que "las empresas de origen italiano parecían casi argentinas" (ibid., p. 414). 
El sentimiento nacionalista, presente en Latinoamérica y a nivel global, obligaba a las empresas extranjeras a tener la habilidad necesaria para entablar empatía con los consumidores regionales. Christopher Tugendhat ilustraba, a raíz de los debates originados en un congreso celebrado por la Cámara Internacional de Comercio en 1969 en Estambul, las precauciones tomadas por varias multinacionales a exponer públicamente su veloz crecimiento para no alarmar a gobiernos y a la opinión pública que las verían como algo distinto (Tugendhat, 1973, p. 25). Olivetti era un fiel ejemplo de la descripción realizada por el autor acerca de este tipo de empresas cuya característica más notable era su estructura de dirección centralizada (ibid., p. 27) ${ }^{22}$ donde "a cada filial se le da la tarea de fabricar una serie particular de productos, y se depende de las otras filiales para los productos restantes. [...] cada filial debe conseguir las máximas economías de escala concentrándose en un trabajo claramente definido y delimitado" ibid., p. 145). Así es como el objetivo de Olivetti era "tener dos fábricas para cada producto; y el resultado es que las máquinas de escribir eléctricas se fabrican en Italia y en EE.UU.; las calculadoras, en Italia y México, y las máquinas de sumar, en Italia y Argentina, por citar tres ejemplos" (ibid., p. 146). En definitiva, dentro del contexto de la Asociación Latinoamericana de Libre Comercio (ALALC) como proyecto de integración regional, Olivetti lograría entonces organizar sus operaciones latinoamericanas asentándose en sus tres países principales: Argentina, Brasil y México (Goldstein y Lluch, 2010, p. 30).

\section{Sumando Merlo}

Sobre un terreno de $123.000 \mathrm{~m}^{2}$ en la localidad de Merlo se proyectó un establecimiento de $31.000 \mathrm{~m} 2$ que albergaría, en 1963, a doscientos empleados y mil operarios para producir, inicialmente, máquinas de escribir, máquinas sumadoras y calculadoras (Imagen 5). A partir de 1968, bajo los acuerdos de complementación de la ALALC, se introduce una especialización en la producción de calculadoras y máquinas contables mecánicas, ${ }^{23}$ cuyo éxito derivó en la ampliación de la planta. El programa edilicio consistía en oficinas administrativas y técnicas, línea de montaje, taller, escuela de aprendices (con aulas, taller, biblioteca y servicios sanitarios), ${ }^{24}$ comedor y cocina, enfermería, guardería, ${ }^{25}$ vestuarios y depósitos. La central termoeléctrica, un pequeño edificio separado, se complementaba con la torre tanque de agua en medio de un parque ${ }^{26}$ con estacionamiento; en otro predio se hallaba el campo deportivo. En el plano publicado tiempo después de su finalización ${ }^{27}$ se encuentran algunas edificaciones de apoyo que se habrían agregado al proyecto original:28 dos porterías, el ya mencionado edificio de nursery (Imagen 6), un edificio de bicicletas, una torre de enfriamiento y una planta de tratamiento de líquidos residuales.

Tal era la expectativa y la confianza en el proyecto de Zanuso que ya en 1959, con el edificio todavía en construcción, la revista italiana Cassabella Continuità publicaba una nota de Roberto Giuducci luego traducida y editada en la revista argentina Nuestra Arquitectura en 1960. Olivetti ya había 
logrado posicionarse como una empresa interesada en dar respuesta a las necesidades sociales de sus empleados. En la publicación de la revista Summa se hacía mención a este hecho con naturalidad, destacando el cuidado otorgado al aspecto social "como en todas las obras de Olivetti". ${ }^{29}$ Respecto a la calidad ambiental el proyecto contenía respuestas tanto para la atmósfera de trabajo deseada de apertura visual e integración espacial como para las instalaciones técnicas cuyo diseño se focalizaba en la conducción adecuada del aire mecanizado. ${ }^{30}$ Se debe destacar la mención que hace Giuducci acerca de los recursos utilizados con el objetivo de lograr un espacio de confort para los obreros: "La máxima atención de los servicios, la atención para crear un ambiente confortable, en las oficinas y la preocupación de proporcionar el mejor ambiente de trabajo, ubicando las reparticiones más numerosas en el perímetro del taller para que la mayoría de los obreros tenga una libre vista al exterior a través de los amplios ventanales" (Giuducci, 1960, p. 29).

En la mencionada publicación de 1960, se halla la planimetría general donde aparece, además de la fábrica, el proyecto de un barrio residencial. El artículo explica: "a través de un espacio verde con instalaciones deportivas, se llega a un barrio residencial, ubicado a espaldas del conjunto, muñido de todas las instalaciones colectivas: hoteles, jardín de infantes, guardería, centro social" (ibid., p. 27). En el plano se ve una zona de unos 220 por 190 metros donde las viviendas se disponen en grupos de entre 7 y 10 unidades en torno a pequeños espacios vacíos y dando frente, a la vez, a las calles y la vía de ferrocarril que limitan el conjunto. Las instalaciones colectivas aparecen en el centro como entidades aisladas. Se destacan dos edificios cuyas sombras acusan mayor altura que se suponen podrían tratarse de los hoteles. Este proyecto nunca llegó a materializarse; en su lugar se construyó el complejo de instalaciones deportivas de Olivetti para uso del personal con su área de estacionamiento.

De todos modos se concretó un proyecto similar, aunque reducido, en una manzana cercana. ${ }^{31}$ Se trata de una escuela y una serie de catorce viviendas individuales dispuestas en torno a un espacio colectivo en el centro de la manzana, donde se encuentra también un tanque de agua con las mismas características del de la fábrica de Zanuso. Las viviendas, todas de la misma superficie y de sobrio lenguaje racionalista, con paños de ladrillo a la vista envolviendo muros de revoque y sencillas aberturas, techo plano acentuado en ligeros voladizos y pérgolas de madera, estaban reservadas para el personal. La diversidad lograda en el conjunto por medio de algunas agrupaciones de a pares con retranqueos diversos respecto al frente alude someramente a ciertas propuestas orgánicas anglosajonas. ${ }^{32}$ La escuela EGB n³8 Ingenieros Camilo y Adriano Olivetti, de similares características y destinada fundamentalmente a los hijos de los trabajadores de la empresa y de similar lenguaje arquitectónico, se encuentra en una de las esquinas del complejo (Imagen 7). ${ }^{33}$ 


\section{Imagen 5}

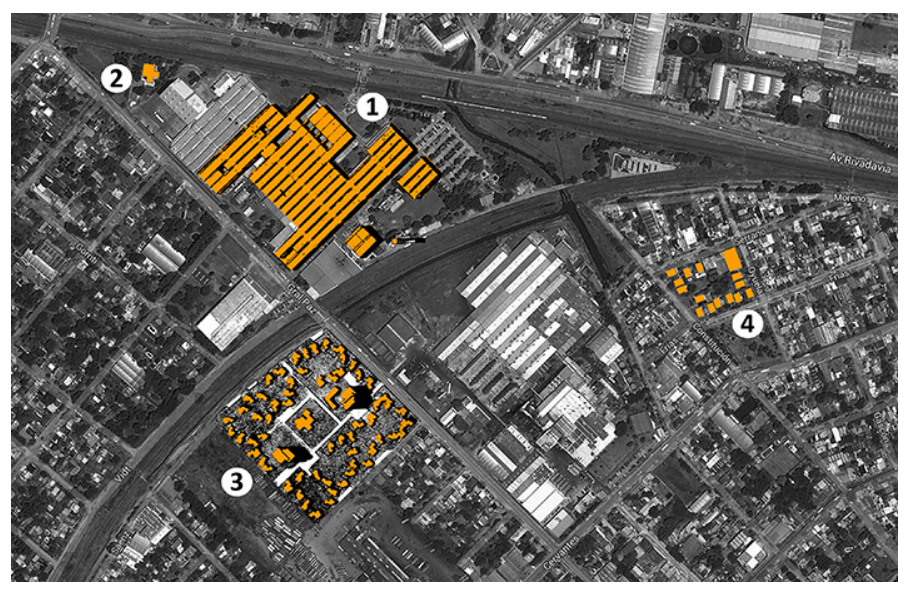

Imagen 6

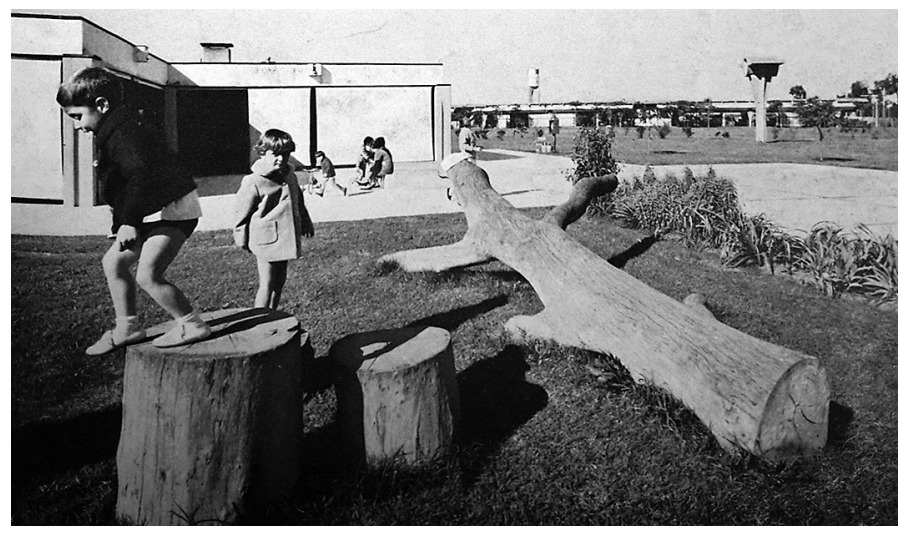

Imagen 7

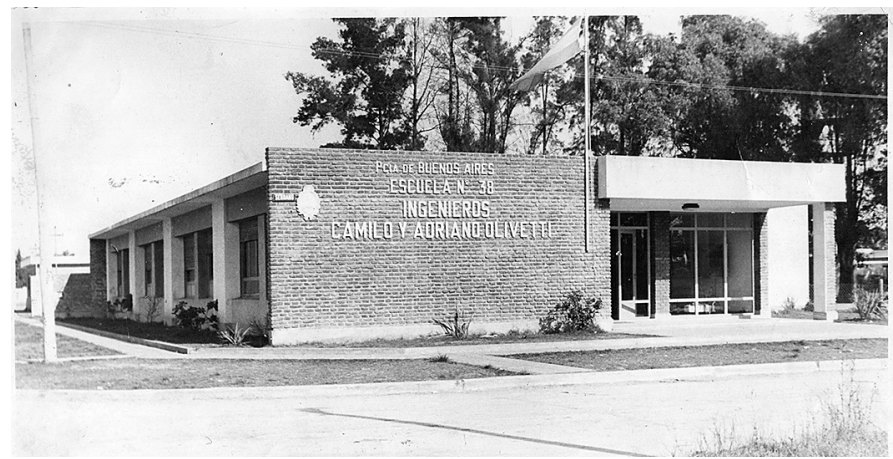




\section{Olivetti, fomento de cultura}

Los intensos debates y manifestaciones culturales de los que fue escenario el país durante la década siguiente a la inauguración de la planta en Merlo son considerados aún hoy por su significativa relevancia y sus implicancias de magnitud incluso política. Los conflictos en torno a la educación protagonizados por los movimientos estudiantiles, condicionantes del devenir del poder del Estado, marcaron el ritmo de los sucesos culturales. Inserta en este contexto, la amplia tarea de promoción y auspicio cultural de Olivetti en Argentina fue emprendida mayormente en ámbitos educativos.

La confianza en la transmisión de saberes como necesidad implícita para el progreso industrial estaba ya presente en la importancia otorgada a las escuelas de aprendices en todas las sedes industriales construidas; de Argentina, con su infraestructura de aulas, taller y biblioteca, no fue la excepción. Como sería de esperar de una empresa peninsular de envergadura radicada en el país, Olivetti también jugó un papel clave, junto a Fiat y Techint entre otros, en el acercamiento cultural entre Italia y Argentina por medio de instituciones educativas de trascendencia como la Asociación Dante Alighieri y la Asociación Cultural Cristóforo Colombo. ${ }^{34}$

Llama en cambio la atención la pequeña Escuela n³8 Ingenieros Camilo y Adriano Olivetti construida en un predio cercano a la fábrica de Merlo y donada al Ministerio de Educación de la Provincia de Buenos Aires. Inaugurada el 25 de junio 1966 nada menos que por el Presidente Arturo Umberto Illia, ${ }^{35}$ en cuyo discurso destacaba la "ciudadfábrica" de Olivetti, ${ }^{36}$ se hallaban presentes también el intendente de Merlo, Francisco Mendiluce, y el gobernador de Buenos Aires, Anselmo Marini, quien en 1964 había restablecido la Dirección General de Escuelas y el Consejo General de Educación, organismos probablemente involucrados con la gestión de la construcción de la escuela (Imagen 8). ${ }^{37} \mathrm{De}$ todos modos, su trascendencia se debe ante todo a los notables aunque poco recordados acontecimientos que albergaría.

Imagen 8

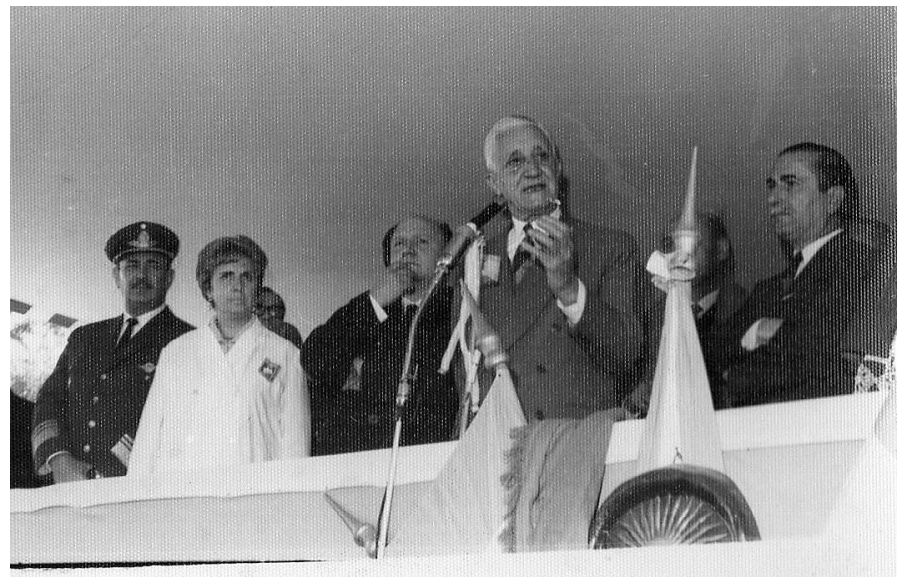


El 7 de abril de 1967 Jorge Luis Borges fue invitado a brindar una conferencia para inaugurar el ciclo cultural de la escuela (Imagen 9). A partir de entonces se realizó allí una serie de conferencias que parecerían desproporcionadas, debido a la importancia de sus figuras y a la cantidad de ellas, para la aparentemente pequeña magnitud de la institución escolar. A Borges lo siguieron Ernesto Sábato, Eduardo Mallea, Silvina Bullrich, Abelardo Arias, Eduardo González Lanuza, Eduardo Zamacois, Leopoldo Marechal junto a Horacio Armani y Miguel Ángel Bustos (Imagen 10), Francisco Luis Bernardez, Bernardo Canal Feijó, Jorge Romero Brest, Conrado Nale Roxlo junto a María Elena Walsh, entre muchos otros. El ciclo proponía también temáticas de música, de pintura, de teatro, de televisión y literatura, convocando a personajes como el compositor Ariel Ramirez (Imagen 11) y la actriz Rosa Rosen. Fue continuado en otros espacios y ciudades del país; así es como, por ejemplo, Cayetano Córdova Iturburu se presentó el 6 de octubre 1967 en San Miguel

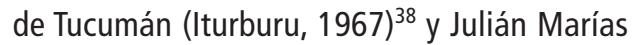
fue invitado en $1970^{39}$ para brindar una conferencia de antropología metafísica en la Capital, Rosario y Córdoba. ${ }^{40}$

Todas estas experiencias fueron recogidas en las Ediciones Culturales Olivetti. Los textos de la versión grabada de las conferencias brindadas en la escuela fueron editados en formato de pequeños libros, algunos de ellos auténticas rarezas literarias pasadas por alto en biografías de los autores. ${ }^{41}$ Se ignora la gestación de estas ediciones, siendo probable que hayan sido realizadas por las mismas oficinas de diseño gráfico de la empresa. Por lo pronto, todas cuentan con el mismo formato y diseño de cubierta con el isotipo de Olivetti creado por Giovanni Pintori en duplicado y en diversos colores según la obra. Dentro de esta colección se conocen también otras publicaciones literarias de Olivetti que no

Imagen 9

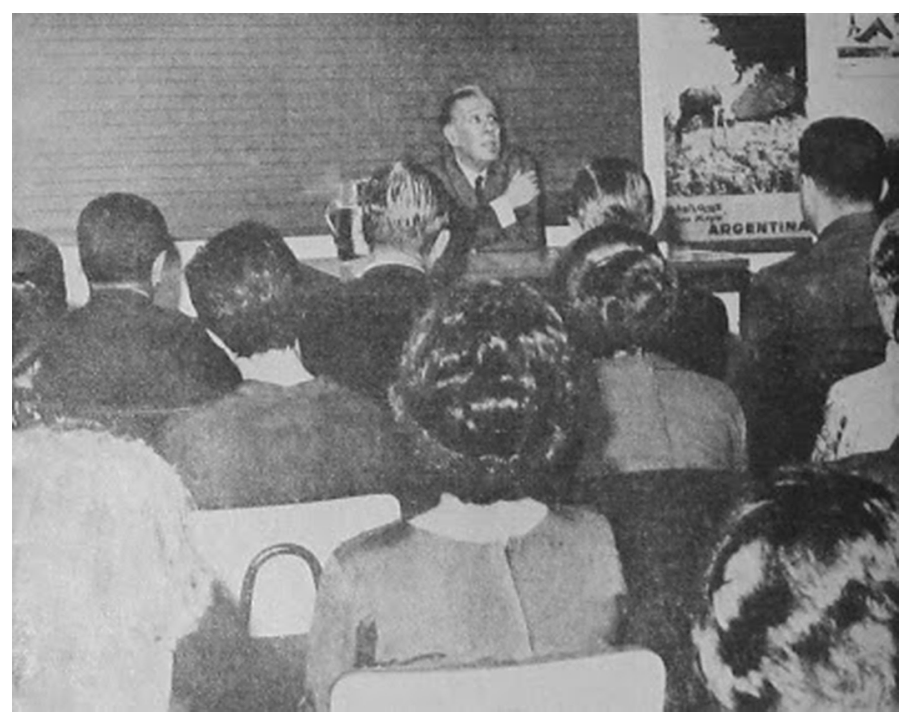


Imagen 10

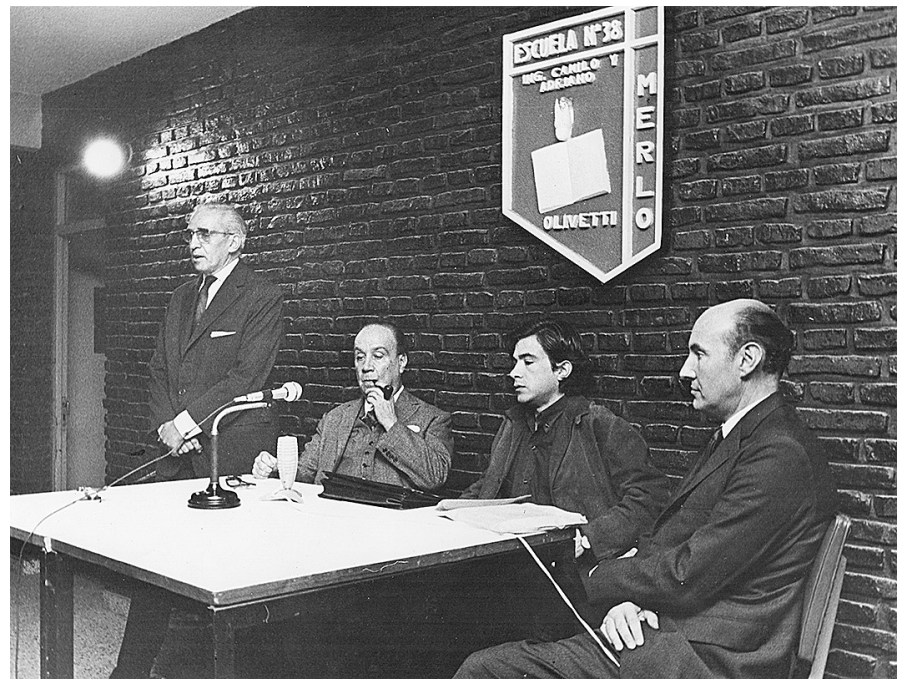

Imagen 11

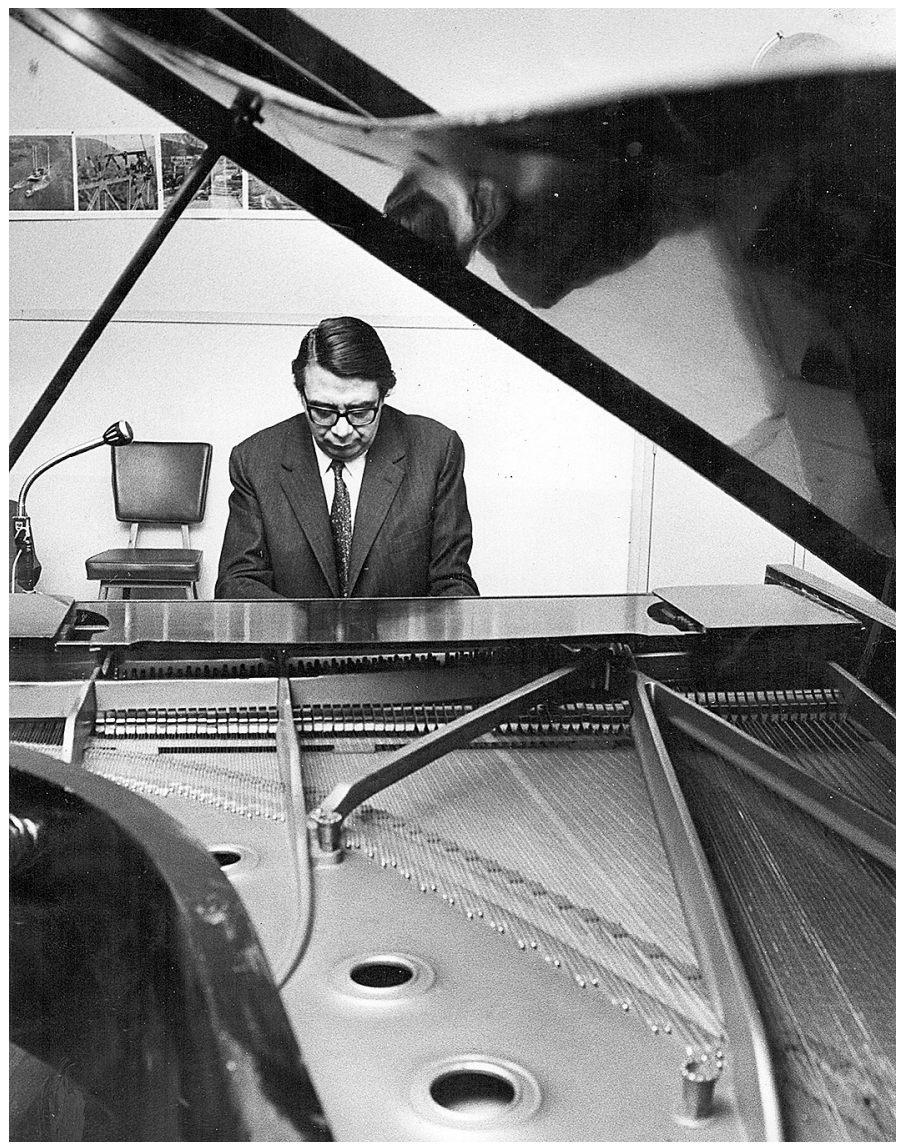


corresponden a transcripciones de conferencias, como la traducción al castellano de "Venecia" de Julián Marías (1971) y "Auca-Nahuel" de Julio Eugenio Cordeviola (1969). La edición en 1968 de dos obras del pintor Carlos Alonso, "Dante" y "La Divina Comedia" fueron distinguidas en la Bienal de San Pablo y en la muestra del libro de Frankfurt representando a la Argentina.

La sola mención de sus protagonistas debiera ser suficiente para rescatar del olvido estos eventos y otorgarles la merecida relevancia en los ámbitos culturales correspondientes. Su temática estrictamente literaria y artística es ajena a otras inquietudes políticas características de gran parte de los debates culturales de la época. Es Ilamativa también la variedad y el antagonismo ideológico de sus expositores, lo cual revelaría un interés cultural amplio y genuino por parte de la empresa Olivetti en Argentina. De todos modos no se pueden dejar de notar cierta red de relaciones sugestivas: la participación de numerosos intelectuales del Grupo Sur o el caso de Jorge Romero Brest, director del Centro de Artes Visuales del Instituto Torcuato Di Tella cuyo Centro de Investigación de Diseño Industrial (CIDI) realizaría una exposición de los productos y elementos gráficos de Olivetti en 1969 mientras al año siguiente aquél ofrecería una conferencia titulada "Nuevas modalidades del arte".

Quizás más recordadas fueron las "Jornadas Adriano Olivetti de Educación" en el Teatro Municipal General San Martín entre el 3 y 8 de agosto de 1970. Patrocinadas por Olivetti Argentina y auspiciadas por el Ministerio de Cultura y Educación de la Nación, contaron con la presencia de especialistas de varios países. La consigna "El cambio educativo en la década del 70" se organizó a su vez en cinco subtemas: "Educación y Economía", "Vías no convencionales de educación", "Educación y Sistemas Escolares", "Educación y Cambio Social" y "Educación Permanente", con una conferencia anexa sobre "La integración del conocimiento en los estudios universitarios"; todos ellos publicados al año siguiente por Ediciones Culturales Olivetti en cinco tomos respectivos. El por entonces Director General de Olivetti Argentina, Luis Borio, hacía mención a la figura poco conocida en Argentina de Adriano a quien caracterizó, evitando el término "mecenas", como una personalidad superadora del empresario en el sentido restringido del término, "consustanciado con su tiempo, con los hombres y con la comunidad" (AAVV, 1971, p. 8). Dentro de un contexto de reacomodamiento de posiciones en el campo educativo signado por el Cordobazo y la caída de Onganía, ${ }^{42}$ las jornadas tuvieron enorme repercusión pública, representando "un momentáneo éxito de esta estrategia de búsqueda de reconocimiento académico y legitimación política" (Susnabar, 2004, p. 185) por parte del gobierno de hecho imperante. ${ }^{43}$ Sin embargo, el tono moderado y optimista de las exposiciones produjo cierta desconfianza entre sectores más politizados acerca del carácter transformador de la acción educativa. La ausencia de debates y de confrontación de posiciones fue una constante en estas jornadas cuya repercusión se debió más bien a la gran cantidad de oradores extranjeros invitados (ibid., p. 171). Con similar ambición extensiva e inclusiva se realizaron previamente, entre el 11 y 19 de octubre de 1969 y en el mismo teatro, unas "Jornadas de actualización en 
planificación, financiamiento y arquitectura del sector salud", auspiciadas por la Secretaría de Estado de Salud Pública, ${ }^{44}$ participando especialistas de Argentina, Italia, Estados Unidos, Inglaterra y Francia. ${ }^{45}$

El alcance institucional y los vínculos de Olivetti con organismos gubernamentales mediante acciones de cultura se evidencian también en los "Premios Olivetti" implementados por la compañía. Así como en Italia tuvieron relevancia los premios Olivetti para Arquitectura y Urbanismo, ${ }^{46}$ en Argentina se instauraron distinciones como el "Gran Premio Literario Olivetti Iniciación" para autores inéditos - cuyo jurado de la primera edición de 1967 formado por Jorge Luis Borges, Julián Marías, Donald Yates, Roger Caillois, Giuseppe Ungaretti distinguieron a "Lo que el diluvio perdona" de Sara María Duhart -, el "Premio José Manuel Estrada", destinado a alumnos de escuelas secundarias y el "Premio Adriano Olivetti Comunidad", para el periodismo argentino; éstos dos en 1968. Existieron también, afín a la voluntad de integrar arte y técnica, premios de pintura y de ingeniería. En 1967 éste último fue otorgado a un grupo de investigación para la localización de una central nuclear. La ceremonia de premiación fue realizada en el ex-Consejo Deliberante de la Ciudad de Buenos Aires ante la presencia del subsecretario de Economía y Trabajo, el presidente de la CNEA (Comisión Nacional de Energía Atómica) y varios directivos de instituciones de ingenieros. La relevancia del trabajo premiado, el sitio del acto y las autoridades concurrentes revelan el posicionamiento de la compañía en la agenda política y científica del país. ${ }^{47}$
Se adivina hasta aquí en los casos mencionados la relación institucional de Olivetti con el poder y su intención de mantener siempre un rol moderado en los debates, dando lugar y permitiendo expresarse a diversas voces. Podría realizarse una interpretación apresurada de esta actitud como estrategia de acomodamiento neutral en una época de enormes tensiones políticas e ideológicas, rechazando incluso todo tipo de confrontación pública que pudiera hacer peligrar los intereses económicos de una industria en expansión de mercado. Quizás en este hilo de pensamiento en búsqueda de razones especulativas del accionar de Olivetti, sería aún más acertado y evidente vislumbrar los fines propagandísticos asociados a estas acciones filantrópicas - hoy día comunes y propias de áreas de responsabilidad social empresarial, aunque escasas por ese entonces -, y que repercutían positivamente tanto en la imagen corporativa percibida por la sociedad como en los mismos productos fabricados. ${ }^{48}$ Las alusiones de la época recogidas reflejan siempre este posicionamiento de por demás logrado como empresa socialmente comprometida respecto al bienestar de sus empleados. ${ }^{49}$ Olivetti era vista como una empresa que no sólo garantizaba un salario justo sino que también proveía un medio ambiente laboral digno a los trabajadores acompañado de variedad de servicios sociales y una propuesta educativa y cultural para sus familias, en su objetivo por mantener una "doble lucha en el campo material y en la esfera espiritual", según las propias palabras de Adriano (Olivetti, 1955, in Olivetti, 1962, p. 135). 
Esta práctica desarrollada en Buenos Aires, sin embargo, debería ser observada también como de natural continuidad y por demás coherente con los criterios fundacionales fomentados desde los mismos orígenes del período de expansión de la fábrica. Como se comentaba anteriormente, la estructura centralizada de la empresa llevaba sus propios directivos a las filiales extramuros ${ }^{50}$ permitiendo la mejor coordinación de los objetivos y estrategias regionales planificados desde Ivrea. Olivetti Argentina Sociedad Anónima Comercial e Industrial, en cuyo plantel directivo abundaban los nombres italianos, no habría de ser la excepción, pero ¿quién asumió la voluntad de difundir las manifiestas ideas del autor de Città dell'Uomo? Será prioritario estudiar aquí la figura de quien fue el posible artífice de este propósito: el ya mencionado vicepresidente y director general de Olivetti Argentina, el abogado italiano Luigi Borio. ${ }^{51}$

En 1964 la familia Olivetti se había visto obligada, en medio de problemas financieros, a ceder el control a un consorcio de bancos y empresas italianas que instalaría a Aurelio Peccei como presidente. Figura destacada del resurgimiento de posguerra italiano y vinculado a empresas como FIAT y Alitalia y fundador de Italconsult y el Club de Roma, delegaría las decisiones locales a Borio, a quien se lo mencionaba en los boletines oficiales como vicepresidente en ejercicio de la presidencia del directorio de Olivetti Argentina. Integrante del Movimiento Comunità, había sido reclutado por el propio Adriano para formar parte de la empresa, ocupando cargos de creciente importancia en diversas sedes de su país hasta hacerse cargo en 1964 de la filial argentina. Es probable que, más allá de sus capacidades y de reunir "las condiciones para ser trasplantado, sin problemas, a otro país", 52 el hecho de conocer y compartir las motivaciones de su mentor fuera un factor de importancia para decidir su nombramiento en un intento de transmitir los valores e ideas de Adriano en Argentina. Confeso lector de Giuseppe Ungaretti, Vicenzo Cardarelli, Federico García Lorca, Stendhal, Carlo Cassola, Ítalo Calvino, Jorge Luis Borges, Ernesto Sábato y Gabriel García Márquez, había sido un aficionado escritor de viajes en su juventud y se pronunciaba, como Adriano Olivetti, a favor del arte, la filosofía y la literatura como dadora de sentido al trabajo diario de las fábricas. ${ }^{53}$ Su oficina del edificio Brunetta atestiguaba la visita de gran cantidad de intelectuales que colaborarían con las actividades culturales de la empresa.

\section{Conclusión}

\section{La conexión desde la Villa Adriana en Ivrea a la ciudad fábrica en Merlo}

El interés por las propuestas regionalistas de planeamiento urbano llevado a cabo y difundido por Adriano en su propio territorio tendría ocasión de ser plasmado en dosis pormenorizadas 0 al menos no orgánicamente articuladas en la sede extramuros de Merlo. La estrategia edilicia priorizaría la ejecución del establecimiento fabril con una propuesta icónica de enorme repercusión mientras las viviendas y la escuela, probablemente iniciativas de organismos ajenos auspiciadas 
por Olivetti, serían la ejecución disminuida de una voluntad mayor nunca realizada. Los hechos no constituirían mayor sorpresa tratándose de una empresa cuyo fin es recaudar dinero de no ser por el empeño dedicado a las actividades culturales emprendidas en los ciclos y jornadas.

Allí es donde se activan los mismos mecanismos de diversidad y amplitud de selección promovidos previamente en Ivrea. Así como a lo largo del tiempo y a través de una variada elección de diseñadores y arquitectos se construyó esa Villa Adriana, esa colección de referencias o museo del futuro regido por un alcalde magnánimo, entusiasta y permeable a influencias que incorporaba múltiples corrientes en la construcción de la identidad visual de la empresa tanto en productos, gráfica y espacios; en su sede externa de Argentina se persiguieron similares objetivos ensayando una suerte de ágora porteña o ciudad-fábrica.
En este último binomio el término "ciudad" se justificaría no tanto por las construcciones residenciales o educativas sino más bien por el rol de espacio de intercambio cultural propio de toda urbe. Si Adriano se había ocupado ante todo de alentar el protagonismo y libertad de acción de cada diseñador y de difundir su nombre en la participación de las realizaciones, nutriéndose así la calidad de la marca Olivetti por medio de la multiplicidad de figuras que formaban parte de ella, de la misma manera entonces, los eventos en Buenos Aires se valieron de la sinergia de sus protagonistas, de la suma del aporte individual de distinguidos intelectuales para visibilizar ante el público local la identidad filantrópica de la institución empresarial. Se repite por lo tanto el collage, la puesta en escena bajo un mismo espacio de pluralidad de ideas y propuestas para reconstruir así un panorama completo de la cultura argentina.

\section{Francisco Sambrizzi}

Universidad Argentina de la Empresa. Facultad de Arquitectura y Diseño. Ciudad de Buenos Aires, Argentina.

franciscosambrizzi@gmail.com

\section{Notas}

(*) Este trabajo se enmarca en el proyecto de investigación UADE/INSOD A14A06 "Fomento y Vanguardia: multinacionales en la Arquitectura Argentina. Los casos de Olivetti y Fiat" dirigido por Mg. Arq. Silvio Plotquin y con la participación de Dra. Arq. Mariana Inés Fiorito.

(1) Se utiliza el concepto expuesto por Françoise Choay (1994).

(2) Véase Choay (1965), Hall (1996) y Fishman (1982). 
(3) La participación tanto en Merlo como en San Pablo del arquitecto italiano Marco Zanuso y sus publicitados resultados no son novedad en la historiografía. Véase Banham (1969, pp. 263-295).

(4) Publicado en 1945 fue la reelaboración del original The Disappearing City de 1932. En 1958 se publicaría la versión final titulada The Living City.

(5) Crítico y editor; fue divulgador en Italia de la obra de Le Corbusier.

(6) El comité directivo estaba compuesto por Giulio Carlo Argan, Sergio Bettini, Pierre Janlet, Riccardo Musatti, Enzo Paci, Geno Pampaloni, Carlo Ludovico Ragghianti, luego se incoporaría Renzo Zorzi. Contribuían Adriano Oivetti, Henry Russell Hitchcock, Paolo Portoghesi, Le Corbusier, Rchard Neutra, Walter Gropius, Paul Rudolph, Esther McCoy, Vincent J. Scully, Siegfried Giedion, Ernesto N. Rogers, Ettore Sottsass Jr, Ricardo Boffil, Oriol Bohigas, entre otros.

(7) Contribuían Giovanni Astengo, Bruno Zevi, Ludovico Quaroni, Giovanni Michelucci, Giuseppe Samonà, Leonardo Benevolo, Manfredo Tafuri, Carlo Aymonino, entre otros.

(8) Grupo formado en 1923 por Clarence Stein e integrado por Benton MacKaye, Lewis Mumford, Alexander Bing y Henry Wright. Sus conceptos fueron implementados principalmente en las comunidades de Sunnyside Gardens, Queens y Radburn, New Jersey.

(9) Corporación federal estadounidense creada en 1933 dentro del contexto de la Gran Depresión para otorgar desarrollo económico mediante la generación de electricidad y control medioambiental al valle del río Tennessee.

(10) Osborn (1950); Mumford (1950); Astengo (1951); Neutra (1953); Gutheim (1953). En otro de los artículos se describe las greenbelts estadounidenses bajo la mirada fotográfica de Gretchen Van Tassel mostrando niños paseando y jugando en espacios al aire libre. Mumford (1953).

(11) Algunos proyectos consisten en grupos de edificios y otros fueron realizados en etapas.

(12) Adriano Olivetti fue electo alcalde de Ivrea en 1956 y diputado en 1958 como representante del Movimiento Comunità.

(13) United Nations Relief and Rehabilitation Administration - Comitato Amministrativo per I'Assistenza ai Senzatetto. Fue una campaña de posguerra de construcción de barrios populares; Adriano fue nombrado presidente en 1959.

(14) Una nota al pie incluida posteriormente a uno de los discursos indica que "en los años 1956 57 el horario de trabajo en todos los establecimientos Olivetti en Italia fue llevado a 45 horas semanales divididas en 5 días formadas de 9 horas: al mismo tiempo los salarios medios entre el 55 y 58 aumentaron en un 9 por ciento" (Olivetti, 1955, in Olivetti, 1962, p. 120).

(15) Según el propio Adriano, en el verano de 1955, 1.539 familias tuvieron prácticamente reduplicados los salarios familiares (Olivetti, 1955, in Olivetti, 1962, p. 135).

(16) En el boletín de noticias de Olivetti número 9 de 1953 menciona "las máquinas producidas son idénticas a las producidas en Ivrea y toda la actividad de la fábrica y de las oficinas siguen el espíritu de la planta madre (Associazione Archivio Storico)

(17) Arquitecto milanés (1916-2001), fue también el encargado de proyectar la fábrica de Olivetti en San Pablo, inaugurada en 1959, y de realizar el diseño, junto a Mario Bellini, de la calculadora de mesa Programma 101 de Olivetti.

(18) Goldstein y Lluch (2010, p. 24) aducen la decisión de construir la fábrica en Merlo en 1954 al hecho de que las ganancias no podían ser repatriadas 
(19) Convenio sobre Emigración (21/2/47), Anexo Sanitario (16/4/47), Acuerdo sobre Migración (26/1/48) y, en otra etapa, el Protocolo adicional de emigraciones y colonización (25/6/52) (Galante, 2008).

(20) Existían políticas para incentivar el crecimiento demográfico equilibrado entre campo y ciudad como el Decreto n. 3721/52 que proponía limitaciones para radicarse en un radio menor a 100 km. de la Capital (Galante, 2008, p. 8).

(21) "La inmigración regulada no es la que el gobierno debe fomentar, de acuerdo con nuestra Constitución” (Bahía Blanca, La Nueva Provincia, 22 de febrero 1947).

(22) Tanto Olivetti como Fiat reclutaban en Italia sus ingenieros, técnicos y cuadros directivos (Devoto, 2008, p. 407).

(23) La sede brasileña produciría máquinas de escribir profesionales y la P101, mientras que la mexicana se dedicaría a máquinas portátiles.

(24) Inicialmente proyectada como edificio aparte, fue luego ubicado junto a la línea de montaje.

(25) Inicialmente proyectada dentro del edificio junto a las oficinas, fue luego construida como edificación aparte junto con el jardín de infantes.

(26) Existen referencias que mencionan que el playground fue diseñado por Roberto Burle Marx.

(27) “Olivetti Argentina”, Summa n. 5, julio 1966, p. 35

(28) Se cuenta con el proyecto publicado en Nuestra Arquitectura (Giuducci, octubre, 1960).

(29) “Olivetti Argentina”, Summa n. 5, julio 1966, p. 34

(30) El edificio atraería la atención de Reyner Banham quien lo tomará como referente en su libro "La arquitectura del entorno bien climatizado" (1969, pp. 263-295).

(31) Conocido hoy como Barrio Ex Olivetti.

(32) En particular a los postulados de Neutra y sus comparaciones con la heterogeneidad presente en los árboles de hojas todas iguales.

(33) En el Boletín Oficial de la República Argentina, 7 de junio 1967 figuran los inmuebles a nombre de la firma Olivetti Argentina S.A.C. e I. En Merlo, además de la fábrica, se menciona un terreno de $41.928 \mathrm{~m}^{2}$ destinado a campo de deportes, doce casas (se contabilizaron catorce el 24 de octubre de 2014 y así lo confirman el resto de las fuentes consultadas) destinadas a viviendas del personal en un terreno de $5.763 \mathrm{~m}^{2}$ con $1.154 \mathrm{~m}^{2}$ de superficie cubierta total, y la Escuela Ingenieros Camilo y Adriano Olivetti de $450 \mathrm{~m}^{2}$ cubiertos con trámite de donación al Ministerio de Educación de la Provincia de Buenos Aires (2014). En el plano catastral de loteo de 1959 figura como propietaria Olivetti Argentina. Debido a la capacidad colmada de una escuela vecina, se habría interesado a la empresa Olivetti para la construcción del edificio, financiándolo casi en su totalidad y dotándolo de mobiliario, según "La escuela 38 Olivetti celebró bodas de plata", artículo periodístico publicado en el diario "Los principios" en 1991 (referencia manuscrita) hallado en los archivos de la Escuela Camilo y Adriano Olivetti, visita 24 de octubre 2014. Se hallaron diversas leyes relacionadas con el desarrollo de este tipo de viviendas. La Ley 6734/64, había aprobado el contrato entre la Provincia de Buenos Aires, el Banco Central y los EE.UU. a través de la Agencia para el Desarrollo Internacional (AID), contemplando la construcción de 1.200 viviendas por el sistema de autoayuda. La Ley 6979/64 promovía la constitución de consorcios para la construcción de viviendas de no más de $60 \mathrm{~m}^{2}$ de superficie cubierta: el Estado aportaría las tierras, asistencia técnica, materiales y equipos (solo o en conjunto con municipalidades o entidades oficiales o privadas). El beneficiario debería pagar la mano de obra. 
(34) Dionisio Petriella, presidente de la Asociación Dante Alighieri de Buenos Aires desde 1945 a 1996 rememora las películas documentales proyectadas en 1965 sobre la pintura italiana realizadas por las oficinas culturales de (Petriella, 1966). Mario Orlando, actual presidente de la Dante Alighieri local y presidente de la Asociación Cultural Cristóforo Colombo en ese entonces recuerda en una entrevista el destacado rol de Olivetti en el patrocinio del nuevo edificio de la Escuela Cristóforo Colombo caracterizando a la empresa como "ángel de la guarda" hasta el punto de nombrar a la flamante aula magna "Adriano Olivetti" en su honor (Orlando, 2014).

(35) Ejerció la Presidencia de la Nación entre el 12 de octubre de 1963 y el 28 de junio de 1966, o sea 3 días después de inaugurada la escuela.

(36) "Inauguró Illia en Merlo una Escuela y un Barrio", artículo periodístico sin referencias hallado en los archivos de la Escuela Camilo y Adriano Olivetti, visita 24 de octubre 2014.

(37) La Ley 6749/64 reglamentó el funcionamiento de ambas instituciones. La iniciativa de la escuela habría surgido de la Comisión Directiva de la Sociedad de Fomento 9 de Julio, la cual habría formado un consorcio en conjunto con Olivetti y la Dirección General de Escuelas, según nota de comunicación del decreto de creación de la escuela, sin referencias, hallada en los mismos archivos de la escuela.

(38) En la página 3 figura "Conferencia pronunciada en la escuela n³8 Camilo y Adriano Olivetti"; sin embargo en la página 4 figura "Texto de la versión grabada de la conferencia de Córdova Iturburu pronunciada en la ciudad de San Miguel de Tucumán el día 6 de octubre de 1967, Ciclo Nacional de Conferencias de Olivetti Argentina 1967".

(39) "El aporte de Olivetti a la comunidad". En: Revista Mercado, 27 de agosto 1970. Luis Mercadante menciona una doble venida en los años 1971 y 1972 (Mercadante, 1974, p. 83).

(40) Tanto entusiasmo produjeron las jornadas que el mismo día del alejamiento de Onganía se computaron 4.000 personas en el Teatro San Martín.

(41) Es el caso de Borges cuyo texto, pocas veces citado, está situado dentro del Tesoro de la Biblioteca Nacional de Argentina.

(42) Juan Carlos Onganía ejerció la Presidencia de facto de la Nación entre el 29 de junio de 1966 y el 8 de junio de 1970.

(43) Roberto Marcelo Levingston estaba por entonces al mando del gobierno. Ejerció la Presidencia de hecho entre el 18 de junio de 1970 y el 22 de marzo de 1971.

(44) “Arquitectura Hospitalaria. Jornadas de actualización en planificación, financiamiento y arquitectura del sector salud”, Summa n. 21, diciembre 1969, p. 46.

(45) Italia contó con la destacada representación de Mario Alberto Coppini, Consejero del Comité Económico y Social de la Comunidad Económica Europea y Presidente del Grupo de Trabajo sobre Urbanización en el Centro de Estudios Ambientales de Roma.

(46) Se otorgaron entre 1955 y 1957, resultando premiados Ignazio Gardella, Carlo Scarpa y Franco Albini en arquitectura, y Luigi Piccinato, Ludovico Quaroni y Giuseppe Samona en urbanismo. 
(47) "El día 6 de julio tuvo lugar en el recinto de sesiones del ex-Concejo Deliberante, el acto de entrega del Premio Olivetti - consistente en la suma global de un millón de pesos y sendas medallas y diplomas individuales - al grupo de profesionales que integró el equipo del Estudio de Preinversión: Central Nuclear para la Zona del Gran Buenos Aires - Litoral. [...] este premio fue instituido por la firma Olivetti Argentina para distinguir, entre los trabajos presentados al $V$ Congreso Argentino de Ingeniería, al que signifique el mayor aporte en beneficio de la comunidad para la República Argentina". El equipo estaba integrado, entre otros, por Jorge A. Sábato, sobrino de Ernesto Sábato (Comisión Nacional de Energía Atómica, 1967).

(48) Como ejemplo, el hecho de relacionar máquinas de escribir Olivetti con los reconocidos escritores participantes del ciclo de conferencias sería una perfecta ecuación.

(49) Además de las referencias respecto a las facilidades edilicias ya mencionadas, Luis Mercadante en 1974 describe que el personal de Olivetti goza "de los más amplios beneficios laborales y sociales" siendo "objeto en sus distintos niveles de procesos y cursos de capacitación" (Mercadante, 1974, pp. 82-83).

(50) En su discurso a los trabajadores de Ivrea en 1955, Adriano mencionaría que "decenas de funcionarios y de dirigentes han pasado de los cuadros italianos a los de las sociedades anexas", haciendo notar también que cada transferencia era comunicada en "Noticias Olivetti" (Olivetti, 1955, in Olivetti, 1962, p. 129).

(51) En los boletines oficiales y en varios medios locales figura argentinizado como "Luis Borio".

(52) "La Escalada de Olivetti", Competencia. Revista quincenal de economía y negocios, N50, 25 de abril 1969.

(53) Adriano Olivetti indicaba su "fe en la virtud liberadora de la cultura, a fin de que los trabajadores todavía demasiado sacrificados por muchas dificultades, salven, día a día, una inferioridad de la que es culpable la sociedad italiana" (Olivetti, 1955, in Olivetti, 1962, p. 134).

\section{Referências}

AAVV (1971). Jornadas Adriano Olivetti de Educación. Educación y Economía. Buenos Aires, Ediciones Culturales Olivetti.

ASSOCIAZIONE ARCHIVIO STORICO OLIVETTI. Olivetti Storia di un'impresa. Ivrea, Italia. Disponível en: www.storiaolivetti.it Acesso em: 6 de out 2014.

ASTENGO, G.(1951). Frank Lloyd Wright in Italia. Urbanistica. Rivista Trimestrale dell'Istituto Nazionale Urbanistica, anno XXI, n. 7, p. 57. Disponível em : http://www.digitallibrary.it/iuav/ BD00153299_6356/index.html?pageNumber=1. Acesso em: 12 out 2014.

BALLENT, A. (2005). Las huellas de la política: vivienda, ciudad, peronismo en Buenos Aires, 1943-1955. Bernal, Universidad Nacional de Quilmes.

BANHAM, R. (1969). The Architecture of the well-tempered environment. Londres, The Architectural Press. 
BOESIGER, W. (ed.) (c1964). Richard Neutra, 1923-50: buildings and projects. Londres, Thames and Hudson.

CASCIATO, M. (1999). "Wright and Italy: The promise of organic architecture”. In: ALOFSIN, A. (ed.) Frank Lloyd Wright: Europe and beyond. Berkeley/Los Angeles/Londres, University of California Press.

CHOAY, F. (1965). L'Urbanisme, utopies et realités. París, Norma.

(1994). "El reino de lo urbano y la muerte de la ciudad". En: RAMOS, A. M. (ed.) (2004). Lo urbano. En 20 autores contemporáneos, Barcelona, Edicions de la Universitat Politècnica de Catalunya. (Versión original: La ville: art et architecture en Europe, 1870-1993. París, Éditions du Centre Pompidou, pp. 26-35).

COCHRAN, T. C. y REINA, R. E. (1965). Espíritu de empresa en la Argentina. Buenos Aires, Emecé.

COMISIÓN NACIONAL DE ENERGÍA ATÓMICA (1967). Boletín Informativo, julio - septiembre, n. 2, año X", p. 9. Disponível em: http://www2.cnea.gov.ar/cac/ci/informes/14cicacBINFOCNEAX2ocr. pdf. Acesso em: 7 out 2014.

CRISPIANI, A. (2011). Objetos para transformar el mundo. Trayectorias del arte concreto-invención, Argentina y Chile, 1940-1970. Bernal, Universidad Nacional de Quilmes.

DE PONTI, J. (2011). Entre la universidad, la empresa y el estado. Trayectorias personales, saberes y prácticas en la génesis del diseño industrial y de la comunicación visual en la Argentina. Décadas 1950 y 1960. Maestría en Ciencias Sociales. La Plata, Buenos Aires, Universidad Nacional de la Plata.

DEVOTO, F. (2008). Historia de los italianos en la Argentina. Buenos Aires, Biblos.

FISHMAN, R. (1982). Urban Utopias in the Twentieth Century: Ebenezer Howard, Frank Lloyd Wright and Le Corbusier. MIT Press paperback edition.

GALANTE, M. A. (2008). La promoción de la inmigración en el primer peronismo y una política específica: las herramientas jurídicas de inclusión para los trabajadores de origen limítrofe. En: PRIMER CONGRESO DE ESTUDIOS SOBRE EL PERONISMO: LA PRIMERA DÉCADA. Mar del Plata, Universidad Nacional de Mar del Plata.. Disponível en: www.redesperonismo.com.ar/archivos/ CD1/EPP/galante.pdf. Acesso em: 4 mar 2014

GIEDION, S. (1954). Walter Gropius: I’uomo e l'opera. Milão, Edizioni di Comunitá.

GOLDSTEIN, A. y LLUCH, A. (2010). "The Italian Economic Presence in Argentina - The Contribution of Multinational Corporations". En: Harvard University \& National Research Council of Argentina (Conicet).

GORELIK, A. (2010). La grilla y el parque: espacio público y cultura urbana en Buenos Aires 1887-1936. Bernal, Universidad Nacional de Quilmes.

GIUDUCCI, R. (1960). "n proyecto a posteriori: la fábrica de Olivetti, del arquitecto Marco Zanuso, cerca de Buenos Aires. Nuestra Arquitectura, n. 371. Buenos Aires. (Traducción de un artículo publicado originalmente en Casabella Continuità n. 229, 1959.)

GUTHEIM, F. (1953). “Clarence S. Stein”. Urbanistica. Rivista Trimestrale dell'Istituto Nazionale Urbanistica, anno XXIII, n. 13, p. 25

HALL, P. (1996). Ciudades del mañana. Historias del urbanismo en el siglo XX. Barcelona, Ediciones del Serbal. 
HALPERIN, T. (2008). La CEPAL en su contexto histórico. Revista de la Cepal, n. 94. United Nations Publications.

ITURBURU, C. (1967). El Movimiento Martinfierrista. Buenos Aires, Ediciones Culturales Olivetti.

LE CORBUSIER (1957). Ronchamp. Edizioni di Comunitá.

(1960). La carta d'Atene. Edizioni di Comunitá.

MERCADANTE, L. (1974). La Colectividad Italiana en la Argentina. Buenos Aires, Alzamor.

MíGUEZ, M. C. (2014). La década del 60: la política interna y las relaciones internacionales de una Argentina convulsionada. Disponível em: http://historiapolitica.com/dossiers/ rriiargentinasesentas. Acesso em: 2 set 2015.

MINISTERIO DE EDUCACIÓN DE LA PROVINCIA DE BUENOS AIRES (2014). Boletín Oficial de la República Argentina, 1967, 2da sección”..Disponible en: www.archive.org/stream/Boletin_Oficial_ Republica_Argentina_2da_seccion_1967-06-07/1967-06-07_djvu.txt. Acesso em: 7 out 2014.

MUMFORD, L. (1934). Técnica y Civilización. Buenos Aires, Emecé.

(1938). La cultura de las ciudades. Buenos Aires, Emecé.

(1949a). Planificazione per le diverse fasi della vita. Urbanistica. Rivista Trimestrale dell'Istituto Nazionale Urbanistica, anno XVIII, n. 1, p. 7. Disponível en: http://www.digitallibrary.it/iuav/ BD00153299_5908/index.html?pageNumber=1. Acesso em: 12 out 2014.. Artículo original en The Town Planning Review.

(1949b). Biografie. Urbanistica. Rivista Trimestrale dell'Istituto Nazionale Urbanistica, anno XVIII, n. 2, p. 59. Disponível em: http://www.digitallibrary.it/iuav/BD00153299_5988/index. html?pageNumber=1. Acesso em: 12 out 2014.

(1950). Biografie di Patrick Geddes. Urbanistica. Rivista Trimestrale dell'Istituto Nazionale Urbanistica, anno XX, n. 6, p. 53. Disponível em: http://www.digitallibrary.it/iuav/ BD00153299_6310/index.html?pageNumber=1. Acesso em: 12 out 2014.

(1954). La cultura delle città. Edizioni di Comunitá.

(1957). La condizione dell'uomo. Edizioni di Comunitá.

(1959). In nome della ragione. Edizioni di Comunitá.

MUMFORD, L. et al. (1953). L'idea della Città Giardino. Rivista Trimestrale dell'Istituto Nazionale Urbanistica, anno XIX n. 3, p. 37. Disponível em: http://www.digitallibrary.it/iuav/ BD00153299_5988/index.html?pageNumber=1. Acesso em: 12 out 2014.

NEUTRA, R. (1953). Lo sviluppo económico ed urbanístico de Guam. Urbanistica. Rivista Trimestrale dell'Istituto Nazionale Urbanistica, anno XXIII, n. 13, p. 17. Disponível em: http://www. digitallibrary.it/iuav/BD00153299_6654/index.html?pageNumber=1. Acesso em: 12 out 2014.

(1954). Planificar para sobrevivir. México/Buenos Aires, Fondo de cultura económica.

(1956). Progettare per sopravvivere. Edizioni di Comunitá.

OlIVETTI, A. (1955). "A los trabajadores de Puzzuoli". In: OlIVETTI, A. (1962). Ciudad del hombre. Buenos Aires, Emecé.

(1956). “Urbanismo y libertades locales". In: OLIVETTI, A. (1962). Ciudad del hombre. Buenos Aires, Emecé. 
OLIVETTI, A. (1957). La arquitectura, la comunidad y el urbanismo. Zodiac, n. 1. In: OLIVETTI, A. (1962). Ciudad del hombre. Buenos Aires, Emecé.

(1962). Ciudad del hombre. Buenos Aires, Emecé.

ORLANDO, M. (2014). “Intervista al Presidente della Dante Allighieri, Mario Orlando”. En: Tribuna Italiana. Disponível em: www.portale.lombardinelmondo.org/nazioni/argurug/articoli/ mondoeconomico/morlan. Acesso em: 7 out 2014.

OSBORN, F. J. (1950). Il centenario della nascita di Ebenezer Howard. Urbanistica. Rivista Trimestrale dell'Istituto Nazionale Urbanistica, anno XIX, n. 3, p. 55. Disponível em: http://www.digitallibrary. it/iuav/BD00153299_6074/index.html?pageNumber=1. Acesso em: 12 out 2014.

PETRIELLA, D. (1966). Problemi degli italiani all'estero. Buenos Aires, Asociación Dante Alighieri.

SCHVARZER, J. (2000). La industria que supimos conseguir. Una historia político-social de la industria argentina. Buenos Aires, Ediciones Cooperativas.

SCRIVANO, P. (1990). Un país más allá de sus fronteras: influencias e ingerencias extranjeras en la arquitectura italiana de la posguerra. 2G, n. 15, 2000/III.

SUSNABAR, C. (2004). Universidad e intelectuales: educación y política en la Argentina (1955-1976). Buenos Aires, Manantial.

TOVAR, A. J. e VALDES de la VEGA, B. (2009). Sobre el Concepto de responsabilidad social de las empresas. Un análisis europeo comparado. Cuadernos de Relaciones Laborales, v. 27, n. 1.

TUGENDHAT, C. (1973). Las empresas multinacionales. Madrid, Alianza Editorial.

ZORZI, R. (1990). Immagini di architetture di Ivrea. Domus, n. 713.

Texto recebido em 7/abr/2015

Texto aprovado em 5/jul/2015 